\title{
Impact of the amount and type of fat and carbohydrate on insulin sensitivity in the RISCK study
}

\author{
Susan Jebb ${ }^{1}$, Les Bluck ${ }^{1}$, Mark Chatfield ${ }^{1}$, Gary Frost ${ }^{2}$, Rachel Gitau ${ }^{3}$, Louise Goff ${ }^{2}$, Bruce Griffin ${ }^{4}$, \\ Margaret Griffin ${ }^{4}$, Fiona Lewis ${ }^{5}$, Julie Lovegrove ${ }^{3}$, Carmel Moore ${ }^{1}$ and Tom Sanders ${ }^{5}$ on behalf of \\ the RISCK Study Group \\ ${ }^{1}$ MRC Human Nutrition Research, Cambridge, UK, ${ }^{2}$ Imperial College, London, UK, ${ }^{3}$ University of Reading, Reading, UK, \\ ${ }^{4}$ University of Surrey, Guildford, UK and ${ }^{5}$ King's College, London, UK
}

Insulin resistance is a central feature in the clustering of metabolic risk factors that predispose to an increased risk of CVD and type 2 diabetes. Reducing SFA intake, through diets either low in fat or high in MUFA has been shown to improve insulin sensitivity (Si) with supervised meals ${ }^{(1)}$. In free-living individuals, whilst Si was significantly impaired on a high SFA intake, the beneficial effect of substituting dietary MUFA was only shown with a total fat intake $<38 \%$ energy $(\% \mathrm{E})^{(2)}$. Diets with a low glycaemic index (GI) may also improve $\mathrm{Si}$ but there is limited evidence for their efficacy ${ }^{(3,4)}$.

RISCK is a multi-centre randomised controlled dietary intervention study in subjects at increased risk of metabolic syndrome (MS) ${ }^{(5)}$. Over a 24-week period subjects followed a high-SFA (HS)-high-GI (HGI) 'reference' diet or one of four isoenergetic interventions: highMUFA (HM)-HGI; HM-low-GI (LGI); low-fat (LF)-HGI; LF-LGI. The target intake for total fat was $38 \% \mathrm{E}$ in the HS and HM diets and $28 \% \mathrm{E}$ in the LF diets, with respective carbohydrate (CHO) intakes of 45 and $55 \% \mathrm{E}$. The HM and LF diets were designed to reduce dietary SFA to $10 \% \mathrm{E}$ with a planned MUFA intake of $18 \% \mathrm{E}$ in the HM diets. The target GI differential between the HGI and LGI groups was approximately 12 points. Dietary targets were broadly achieved with clear segregation between diets ${ }^{(6)}$. An intravenous glucose tolerance test (IVGTT) was conducted at 0 (visit 1) and 24 (visit 2) weeks of the intervention. Modelling of the IVGTT data (MINMOD Millennium programme, version 6.02) was used to calculate Si and other variables of glucose metabolism. Quantitative insulin-sensitivity check index (QUICKI) was calculated from fasting measures of glucose and insulin.

A total 548 of 720 participants completed the study; thirty-eight subjects were excluded from the analysis because of incomplete IVGTT data $(n 4)$ or unsuccessful modelling of data $(n 34)$. There were no significant effects of the intervention on Si or other variables of glucose metabolism.

Table. Mean change* in measures of insulin sensitivity, glucose disposal $(\mathrm{Sg})$ and insulin secretion $(\mathrm{AIRg})$

\begin{tabular}{|c|c|c|c|c|c|c|c|c|c|c|c|}
\hline & \multicolumn{2}{|c|}{ HS-HGI ( $n$ 78) } & \multicolumn{2}{|c|}{ HM-HGI $(n$ 106) } & \multicolumn{2}{|c|}{ HM-LGI ( $n$ 105) } & \multicolumn{2}{|c|}{ LF-HGI $(n$ 112) } & \multicolumn{2}{|c|}{ LF-LGI ( $n$ 109) } & \multirow[b]{2}{*}{$P$} \\
\hline & Mean & $95 \% \mathrm{CI}$ & Mean & $95 \% \mathrm{CI}$ & Mean & $95 \% \mathrm{CI}$ & Mean & $95 \% \mathrm{CI}$ & Mean & $95 \% \mathrm{CI}$ & \\
\hline Insulin (pmol/l) & -0.2 & $-7.5,7.6$ & 0.4 & $-5.7,7.0$ & -2.8 & $-8.2,2.9$ & -6.5 & $-12.4,-0.1$ & -7.2 & $-12.8,-1.3$ & $0.11 \dagger$ \\
\hline Glucose $(\mathrm{mmol} / \mathrm{l})$ & -0.2 & $-1.6,1.1$ & -1.8 & $-3.3,-0.4$ & -2.1 & $-3.2,-0.9$ & -2.3 & $-3.3,-1.2$ & -2.2 & $-3.3,-1.1$ & 0.11 \\
\hline QUICKI & 0.1 & $-1.2,1.4$ & 0.3 & $-0.7,1.4$ & 0.8 & $-0.2,1.8$ & 1.5 & $0.4,2.6$ & 1.3 & $0.2,2.3$ & 0.11 \\
\hline $\mathrm{Si}(/(\mathrm{mU} / \mathrm{l})$ per min $)$ & -4.1 & $-12.7,5.3$ & 2.1 & $-5.8,10.7$ & -3.5 & $-10.6,4.3$ & -8.6 & $-15.4,-1.1$ & 9.9 & $2.4,18.0$ & 0.13 \\
\hline $\mathrm{Sg}(/ \mathrm{min})$ & 2.1 & $-5.5,9.8$ & -2.0 & $-9.2,5.2$ & 1.9 & $-5.3,9.2$ & 4.9 & $-2.8,12.6$ & 0.2 & $-5.8,6.3$ & 0.83 \\
\hline AIRg (mU/1 per min) & $7.6-$ & $-2.5,18.3$ & 10.8 & $3.4,18.5$ & 2.4 & $-5.4,10.6$ & -0.1 & $-7.5,7.7$ & 0.9 & $-6.2,8.3$ & 0.13 \\
\hline
\end{tabular}

*Calculated on transformed scale, but expressed as \% change from median value at visit 1. Outliers first removed (transformations: log (glucose), log (insulin), 1/QUICKI, 1/RQUICKI, $\left.\log (\mathrm{Si}),{ }^{3} \sqrt{ }(\mathrm{AIRg})\right)$.

$\dagger$ From ANCOVA of visit 2 measure on visit 1 measure adjusted for gender, centre, ethnicity, waist, $\log (\mathrm{HDL})$, age.

In the present study isoenergetic manipulation of the proportion of fat and CHO, the proportion of SFA and MUFA or the GI of the diet does not have a major effect on $\mathrm{Si}$ in subjects at increased risk for MS.

The RISCK study was funded by the Food Standards Agency (NO2031).

1. Perez-Jimenez F, Lopez-Miranda J, Pinillos MD et al. (2001) Diabetologia 44, 2038-2043.

2. Vessby B, Unsitupa M, Hermansen K et al. (2001) Diabetologia 44, 312-329.

3. Frost G, Leeds A, Trew G, Margara R \& Dornhorst A (1998) Metabolism 47, 1245-1251.

4. Aston LM, Bluck L, Stokes C, Jackson S, McKenna L \& Jebb SA (2007) Int J Obes (Lond) 31, Suppl. 1, S28

5. Jebb SA, Frost G, Griffin BA, Jebb SA, Sanders TS \& Lovegrove JA (2007) Nutr Bull 32, 154-1566.

6. Moore C, Farrant H, Gitau R, Goff L, Griffin M, Lewis F \& Lovegrove J (2008) Proc Nutr Soc 67, E311. 